\title{
Developing a Systematic In-house Training Program for Integrated Library Systems
}

\section{Stuart Glogoff and James P. Flynn}

\begin{abstract}
Staff training to enhance implementation of an integrated library system (ILS) should be tied to organizational goals and relevant management principles. Training methods should be scrutinized, and several key factors considered when developing a staff training program for an ILS. Among the important factors reviewed in this article are applying andragogic learning theory, employing effective on-the-job training techniques, selecting trainers for their competencies rather than their availability, and providing visible administrative support during all phases of the staff training project.
\end{abstract}

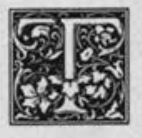

he University of Delaware Library is conducting a comprehensive staff training program as an integral part of implementing its integrated library system (ILS). This program was necessitated by such factors as limited vendor training; the need to recruit system trainers from among the staff; and the recognition that staff training for an ILS required far more planning than for single-function automated systems and that staff training is an ongoing project because of personnel changes and future system enhancements. The development of a "train-thetrainers" program entailed a comprehensive needs analysis review, some attention to management principles, a thorough evaluation of existing adult training practices, and the application of relevant learning theory to the training environment. This paper discusses the important link between applied learning theory and the program's overall development.

\section{BACKGROUND}

Implementing an ILS entails a variety of activities, among which staff training is one of the most crucial. ${ }^{1}$ Yet, planning, designing, and presenting a systematic staff training program in tandem with ILS implementation is not a regular practice. ${ }^{2,3}$ Reports of user education programs for the online catalog have caught the most headlines, ${ }^{4}$ while in-house training programs specifically designed for library staff have evolved more from necessity than from strategic planning. A literature search for articles addressing staff training for an ILS turns up little. For the most part, there is cursory treatment of the topic in the many works that cover planning, procuring, and implementing automated systems. Regrettably, few articles do more than acknowledge the need.

Urbanek points out that this scarcity of information is surprising in light of the voluminous treatment the subject receives in business and education, and considering

Stuart Glogoff is Head of the Systems Department in the University Library, and James P. Flynn is Director of Personnel Services at the University of Delaware, Newark, Delaware 19717-5267. 
libraries' commitment to automation. ${ }^{5}$ Many library managers may rely on a vendor to provide training without considering long-term training needs. Descriptions of staff training for an ILS center on the use of vendor manuals and on vendor personnel who provide hands-on training to a limited number of staff members. ${ }^{6}$ In addition, some libraries designate a small number of people to serve as core trainers. The vendor trains these individuals who then have responsibility for instructing the rest of the library's staff. ${ }^{7}$ Boss observes that libraries doing this "appear to have better ongoing training programs. ${ }^{18}$

Some descriptive discussions of staff training suggest guidelines for developing a formal in-house training program. Communication, in the form of a series of staff orientations and a periodic newsletter, is important. The number of participants attending each training session should be kept to a minimum. (A standard might be maximums of two persons per terminal and three terminals). Sessions should include extensive hands-on experience, be conducted as a series of briefings that build upon previous related training, focus on a specific set of related functions or techniques, allow practice time between sessions, and provide a mechanism for feedback to evaluate success. ${ }^{9,10}$ Since job tasks differ, training sessions may vary in content, length, and frequency. In addition, it is essential to ensure that the training methodology is consistent from trainer to trainer. ${ }^{12}$

Implicit in the development of any staff training program is the assumption that the training will contribute directly and effectively to the achievement of overall organizational goals. Certainly, a primary obligation of any manager is to define the mission or purpose of the organization in terms of the clientele it serves. After the organizational mission has been defined, an operation system can be constructed to set major goals, clarify specific objectives, and arrange all subordinate activities into logical action steps contributing to the achievement of those goals. Odiorne argues that staff training, like any other organizational activity, must be goaloriented, directed toward future

\begin{abstract}
"Birnbrauer points out that on-thejc. $b$ training is among the most expensive and least effective training methods used and whimsically compares it to the game of whispering a story in one person's ear and passing it around the room."
\end{abstract}

effectiveness, and responsive to client interests. ${ }^{13}$ By establishing training objectives and selecting learning activities that enable trainees to acquire and improve job-related ILS proficiencies, the manager contributes to organizational goals and forges a direct link between improved staff performance, client satisfaction, and optimum exploitation of the library's resources. $^{14}$

\section{PROBLEMS OF ON-THE-JOB TRAINING}

On-the-job training has certain shortcomings that may negatively effect a formal training program. Birnbrauer points out that on-the-job training is among the most expensive and least effective training methods used and whimsically compares it to the game of whispering a story in one person's ear and passing it around the room. ${ }^{15}$ Creth states that in cases when staff are not well trained, a self-training process, which frequently results in incorrect information and poor performance, may occur. ${ }^{16}$ She further notes that learning by "observation or with a seat-of-thepants approach is increasingly difficult in the more complicated automated environment of most libraries. ${ }^{\prime 17}$ Such limitations must be addressed because well-prepared staff reduce production-related problems and work-flow interruptions. What, then, must a trainer know in order to be effective?

\section{ADULT LEARNING THEORY}

Historically, learning has been conveyed through the passage of knowledge from one individual to another. Skills acquisition, likewise, has followed the classic pedagogic model. This model em- 
bodies the theory and practice of an almost exclusively teacher-dominated paradigm. Under a pedagogic learning system, the student is highly dependent upon the teacher for information, skills acquisition, or basic direction in the course of study. Curricula tends to be uniform and change only in the sense that a more experienced learner is expected to handle more complex instruction and demonstrate broader problem-solving skills. Needs assessment, curriculum planning, course design, and learner evaluation are determined unilaterally by the instructor. As student, one's interest in any particular subject has little to do with why it is studied; rather, one learns because others think it is important. Because the pedagogic is the learning model with which most adults are familiar, it becomes the model imitated most easily when shifting roles from student to teacher. This is important to remember when planning and designing a "train-the-trainers" program.

Many current experts in educational technology (particularly those influenced by Carl Rogers and Malcolm Knowles) argue that the classic pedagogic model is inappropriate for most adult learning activities. These authorities contend that adults learn best through a complex process that includes references to past experiences, acceptance of the value of the learning, involvement in directing the process, and hands-on experimentation in a nonthreatening environment. ${ }^{18,19}$ In such a system, the role of the trainer becomes primarily that of a resource, someone who supports and validates the competency of the self-directed learner. This experiencebased learning methodology is termed andragogy.

Because few trainers are familiar with the distinctions between a pedagogic and an andragogic approach to instructing adults, it is important to contrast differences between the two methodologies. An andragogical instructional style, for example, allows trainees to acquire online cataloging skills at their own pace. Further, the trainer's primary role is that of a technician/resource person available to trainees as needed. Trainers maintain a supportive and nonthreatening environ- ment in which each adult trainee can function most effectively. By practicing adult learning theory the trainer will be more attuned to how adults learn and will be alert to the four typical problems described by Reynolds: (1) trainees who are afraid of the system, (2) trainees who resent having to learn to use it, (3) trainees who approach it with reckless abandon, and (4) trainees who have such a strong mental block that they simply cannot learn to use it effectively. ${ }^{20}$ Trainers must recognize that adults want their learning to be problem-centered, personalized, and responsive to their need for self-direction. ${ }^{21}$

To enrich their trainees' learning experiences, trainers must acquire effective listening skills and questioning techniques. They need to understand the importance of providing feedback to trainees in descriptive terms rather than as evaluative statements. Knowles remarks that the traditional educational rhythm of lecture/discussion has given way to a more natural process in which a learner's previous experiences, coupled with a desire for supportive, self-paced, skills acquisition, can make the job of a staff trainer not only more effective but also more personally rewarding. ${ }^{22}$ Closely related to this is the importance, particularly when working with a problem trainee, of providing one-onone training, which has been found to be the advantageous method of preparing a person to operate equipment or do a specific task. ${ }^{23}$

One-on-one training techniques are significant for several reasons. Their use offers trainers the opportunity to reiterate the importance of creating a positive attitude in the trainee toward any skillsacquisition process. Trainers can also explain how and why such new skills will make the trainees more productive members of the organization. Finally, any instructional strategy based on andragogic principles assumes that each trainee, after receiving an overview of the online system, will invest a block of learning time in self-paced skills-acquisition exercises. Consequently, the trainer's orientation must be directed toward responding to trainees, and there is little reason to stress such traditional skills as lecturing. 


\section{"Administratively, it was felt that if we erred, it would be better to overin- volve staff in the needs assessment process than to overlook them."}

Of course, to presume that there is any one best way to educate all adults would be a misleading oversimplification of learning theory. Researchers such as Brookfield concur that the most effective adult education occurs when there is voluntary participation, mutual respect between trainer and learner, a collaborative spirit pervading the learning environment, ongoing interaction between all parties, frequent opportunities for critical reflection and performance review, and self-directed learning after the initial orientation session. ${ }^{24}$

\section{APPLICATION OF ADULT LEARNING THEORY}

\section{Needs Assessment}

Many of the University of Delaware Library's staff already were experienced with various automated systems; collectively, these experiences offered much from which to draw in developing an effective training program. The circulation department labored with a batchprocessed system for nearly fifteen years; cataloging has used OCLC since 1973; the acquisitions department served as a test site for OCLC's online acquisitions system in 1981 and had used it since; the reference department and branch libraries have conducted bibliographic database searches for over a decade along with searches of OCLC and RLIN; and interlibrary loan has participated in the OCLC ILL subsystem.

Rather than presume to know the staff's experience or what techniques to incorporate in our training program, a needs assessment instrument was distributed. Inviting staff to complete the training questionnaire was also a form of public relations. Each individual's experience became important to the success of the training program. Administratively, it was felt that if we erred, it would be better to overinvolve staff in the needs assessment process than to overlook them.

The needs assessment questions focused on each staff member's experience with automated library systems. Questions addressed types of prior training as well as strengths and weaknesses of programs and invited comments on what to include-and avoid-in training. Of the 75 questionnaires sent out, there were 51 responses, from which came valuable information that was later applied to constructing the training program.

To the first question, Have you been trained to use an automated system?, 40 of the 51 respondents answered yes and indicated training on more than 20 different systems. This information offered the possibility of drawing upon a great breadth of experience.

Question 2, What type of training did you receive in order to work on the system?, included 8 options-staff were asked to check all that applied. The responses indicated that 30 had been trained by a coworker and 26 by a supervisor; 32 had learned by following instructions in a manual; 39 , on-the-job; 6 , through computer-assisted instruction; 3 , with a programmed text; 11 , in formal course work; and 14, in a vendor-conducted workshop. The responses indicated that nearly all had received training either from a supervisor or coworker or on-thejob. This fact led to the conclusion that good and bad techniques may be practiced and reinforced with each generation of employees.

Question 3, Did you feel that you needed a better background in library functions and automation in general to make the training more meaningful?, attempted to determine how important staff development workshops might be in preparing staff members for training on the system. Ten respondents answered yes, and 33 said no to this question. In a general section of the questionnaire, staff were asked Would you attend a basic-level training workshop?, and a few topics were listed. Responses indicated considerable interest in workshops on automation terminology and explanations of hardware 


\section{"It is not adequate to entrust the com- position of a workplace training staff to the unpredictable results of asking for volunteers."}

and software and how they interact, as well as in the library's relationship to campus computing services.

The next few questions addressed training techniques. To the question Did you have sufficient opportunities to ask questions?, the response was unanimous (42 yes, 0 no). An open-ended question, What did you consider the single best teaching technique that you would recommend for use in vendor training?, was followed by What would you urge be avoided during vendor training? and a call for additional comments. Staff overwhelmingly requested small-group training with much hands-on experience and strongly voiced their disapproval of large lectures without practice time.

Information from the needs assessment clearly demonstrated that the majority of staff with prior automated library system training had received instruction through on-the-job sources. This variety of training experience may have been adequate, but there is no indication that it was conducted from an instructional perspective that acknowledged the need to present technical information to adults in a manner that recognizes their unique life experiences. Furthermore, with staff overwhelmingly requesting small-group instruction and hands-on experience, the need for an andragogic approach was underscored.

\section{Selecting Trainers}

The success of any staff training program rests, in a large part, on the competencies, expertise, and motivation level of individual trainers. It is not adequate to entrust the composition of a workplace training staff to the unpredictable results of asking for volunteers; nor is it adequate to request that unit supervisors designate the candidate(s) of thei. choice. Otto and
Glaser recommend that instructors be selected for their strong interest in people, professional stature, and proven ability to present detailed instruction in a clear, nonthreatening manner. ${ }^{25}$ Tracey argues for a more systematic selection process featuring development of training expectations based on organization goals, endorsement from the unit administrator, subject-matter expertise, peer respect, communication skills, self-confidence, emotional stability, and flexibility. ${ }^{26}$

The information reported in the training questionnaire provided a foundation upon which to build a training program. Eighteen individuals, appointed as the core group of trainers, were selected by the library's three assistant directors and represented all library departments. This was done for two reasons: to guarantee a broad base for the training program and to ensure that each department would have one person well-versed in the system for coworkers to consult as an internal resource.

Once the trainers were appointed, the immediate question was how best to prepare them for the task ahead. The program proposed more than simply training other staff members to use the system. Because there was no existing mechanism upon which to build the training program, one needed to be developed. Considerations included local manuals, customizing procedures, training new staff, updating experienced staff, retraining all staff as enhancements are implemented, exploring opportunities for computer-assisted instruction, and evaluating the program.

\section{Training the Trainers}

The university provides excellent support in instructional areas to its administrative and academic departments. Staff in the personnel employee relations office offer professional development workshops to faculty and staff in numerous areas, including teaching and training effectiveness. A specialist in this subject was asked to present a series of workshops on sound training techniques. This series was developed with three major themes, each of which eventually became the basis for a separate workshop: (1) basic con- 
cepts in adult learning theory, (2) acquisition of training skills, and (3) practical tips for implementing these skills when designing or conducting staff training.

Because most of those selected to conduct online catalog training for the University of Delaware Library were not familiar with the distinctions between a pedagogic and an andragogic approach to instructing adults, the first workshop explored those differences. Workshop participants had the opportunity to discuss the fact that an andragogical instructional style would allow trainees to acquire online cataloging skills at their own pace. Further, the trainers needed to acknowledge their primary roles as technicians/resource persons available to trainees on a consultant basis. Trainers concentrated their energies on maintaining a supportive and nonthreatening environment in which each trainee could function most effectively.

This need to attend to the learning environment was stressed continually during the first workshop. As John Diebold has pointed out, automated information technology is a mixed blessing to many organizations. The obvious long-term benefits to be gained from a computer-literate work force can easily be offset by employees' anxiety toward things new or different. Feelings of "machine" alienation, lack of self-worth, and fear of failure are common during the learning phases of any computer-based systems implementation. ${ }^{27}$ Workshop participants were also required to read a short article that reiterated adult learning theory and presented some training tips upon which to base the next workshop.

The second workshop examined skills by which trainers could enrich the learning experiences of their trainees. Participants practiced effective listening skills and questioning techniques and reviewed the importance of providing feedback to trainees in descriptive terms such as "Pressing RETURN at this point won't provide the information you want," rather than the evaluative statement "You must not have been listening this afternoon or you would have known better than to press RETURN now." Participants discussed in detail Wiley's advice regarding proper techniques for one-on-one training. His article was significant because it (1) reiterated the importance of creating a positive attitude toward any skills-acquisition process and (2) urged explanations of how and why such new skills would make trainees more productive and valuable members of the organization. At the conclusion of the second workshop, participants were given reading materials on training program design; ${ }^{29}$ they also were asked to reflect on the quality of the user training they were about to receive from the system vendor.

The third workshop began with a short critique of the vendor training that all participants had received. They felt this training was satisfactory but oriented too much toward an expectation that trainees would progress through the session at the same place. Several mentioned specific situations in which the directive instructional technique used by the vendor resulted in making the group wait while one person's questions were answered. These observations, along with a thorough discussion of David Cram's recommendations ${ }^{30}$ for designing the "ideal" training course, led to the development of two distinct tracks for the library's staff training program.

\section{Lesson Design}

Following the workshops, trainers convened in two groups to concentrate on lesson design: one group addressed staff training on the online catalog and the other, the cataloging component. Each prepared a syllabus, sample searches, training aids, and practice exercises. Concepts discussed in the earlier workshops were applied; for example, each lesson was limited to no more than six participants using three terminals. Sessions began with an orientation outlining that lesson's objectives. Trainees were assured that there would be much hands-on experience, consistent exposure to the system, and opportunities for questions. The trainers also decided that a good technique for alleviating fear was to tell all trainees that there was nothing they could do to harm the system.

Other useful applications of adult learn- 
ing theory were employed. Catalogingcomponent trainers reinforced the relevance of past experience by calling for comparisons between cataloging on OCLC and the new system. Both groups emphasized an interactive concept in which the machine was assisting the individual to use the ILS. Blocks of practice time were set aside so that all trainees could finish their exercises and work on the system at their own pace in a nonthreatening environment-a trainer was available but not conspicuous.

Once the online catalog training was completed, a questionnaire soliciting feedback was distributed to all staff members. Its intent was to gauge staff response to the sessions and to learn if staff felt the trainers were well prepared. Forty-seven questionnaires were returned, and the responses indicated that the staff were, for the most part, pleased with the sessions. In response to the first question, How would you rate the overall value of your training session?, there were 13 "excellent," 24 "very good," 8 "satisfactory," and 2 " unsatisfactory" responses. Briefly reviewing other responses, 45 found that the training was presented in a clear and logical format, 38 found the trainer well prepared, 46 had sufficient time to ask questions, and 44 found their trainers responsive to the questions that were asked. Similarly, staff found the handouts clear and helpful. Finally, 42 felt that the training did prepare them adequately for using the online catalog. An open-ended comments section drew few responses. This feedback indicated strong support for the direction taken by the staff training program.

The training programs developed for the online catalog and for cataloging provided a theoretical background and the necessary mechanics. These principles were subsequently included in sessions for advanced cataloging and in a program on the technical services component for public service staff. Because application of andragogic learning theory worked so well, it has been applied to two staff training projects under development. One is a skills workbook for new technical services employees; the second is an interactive, computer-based education program on the circulation component. Both present a learning experience that is interactive and self-paced and conducted in a nonthreatening environment.

\section{OBSERVATIONS AND RECOMMENDATIONS}

Successfully training staff on a newly implemented ILS can be a timeconsuming affair that touches every library department. The successful inhouse training program should have a training coordinator with the authority necessary for maintaining the responsibility and full administrative support. ${ }^{31}$ As Reynolds wrote, "Assigning training duties to whoever on the staff happens to be the most available at a particular time will not suffice. ${ }^{\prime 32}$ Conversely, adding the responsibility of conducting a training program to an already busy employee may place that person in the position of being unable to dedicate adequate time to other responsibilities. This has been mentioned as a frequent problem in information centers. ${ }^{33}$

Additionally, it is crucial for trainers to know that their appointment to the training program carries real responsibility. Supervisors must respond appropriately to several key factors: many people who train other employees do not consider themselves to be in a learning delivery role. Instead, they see themselves strictly in terms of their primary work assignment. ${ }^{34}$ Training priorities and goals must be clearly stated, progress monitored regularly, and contributions recognized. Supervisors must understand that trainers need time away from normal duties to practice on the system and to work on planning the program.

American employers provide at least 17.6 million formal courses each year to almost 15 million trainees. ${ }^{35}$ For the library as employer, providing staff training on the ILS must be recognized as a necessary expense. It is also a critically important activity that clarifies and strengthens the relationships among organizational mission, long-range planning, project accountability, and professional development. Viewed in light of these consider- 
ations, staff training should receive significant attention by library administrators when planning and implementing an ILS.

Projections indicate that by 1990 the majority of medium and larger libraries in North America will be automated. ${ }^{36} \mathrm{Li}$ brary automation will affect the manner in which virtually all staff members perform their jobs and staff members will play an increasingly larger role in information retrieval. Creth considers that the significant role staff play in "creating a dynamic future for libraries" requires supervisors to pay serious attention to the job training process. ${ }^{37}$ There is no doubt that libraries must now address the question of how best to prepare staff for the changes ahead. The authors suggest a program that emphasizes workshops on adult learning techniques, skills acquisitions, performance measurements, program design, and short- and long-term training objectives. These components are readily transferable to other libraries.

\section{REFERENCES}

1. Dennis Reynolds, Library Automation: Issues and Applications (New York: Bowker, 1985), p. 270.

2. Donald J. Sager, Public Library Administrators' Planning Guide to Automation (Dublin, Ohio: OCLC, c. 1983$),$ p. 38 .

3. Kenneth E. Dowlin, The Electronic Library: The Promise and the Process (New York: Neal-Schuman, c. 1984), p.109.

4. Elaine Coppola, "Who Trains the Trainer? Library Staff are OPAC Users, Too," Library Hi Tech 1:3 (Winter 1983).

5. Val Urbanek, "Staff Training and Automation: Issues and Concerns for Library Managers," in Microcomputers in Libraries, ed. Ching-chih Chen and Stacey E. Bressler, (New York: NealSchuman, c. 1982), p.157.

6. Joseph R. Matthews, ed., A Reader on Choosing an Automated Library System (Chicago: American Library Assn., 1983), p.201.

7. Naomi C. Broering and others, Computers and Libraries: A Management Seminar (Washington, D. C.: Georgetown Univ. Medical Center, c. 1982), p.139.

8. Richard Boss, The Library Manager's Guide to Automation, 2d ed. (White Plains, N.Y.: Knowledge Industry, c. 1984), p.112.

9. Reynolds, p. 275 .

10. Broering, p.140.

11. Matthews, p.201.

12. Carol Tenopir, "An In-House Training Program for Online Searchers," Online 5:21 (May 1982).

13. George Odiorne, Training by Objectives: An Economical Approach to Management Training (New York: Macmillan, 1970), p.96-106.

14. Ronald Szczypkowski, "Objectives and Activities," in Alan B. Knox, Developing, Administering and Evaluating Adult Education (San Francisco: Jossey-Bass, 1980), p.37-56.

15. Herman Birnbrauer, "Are We Ready For Hi-Tech?" Training and Development Journal 39:4 (Sept. 1985).

16. Sheila D. Creth, Effective On-the-Job Training: Developing Library Human Resources. (Chicago: American Library Assn., 1986), p.9.

17. Ibid.

18. Malcolm S. Knowles, The Adult Learner: A Neglected Species, 2d ed. (Houston: Gulf, 1978).

19. Carl R. Rogers, Freedom to Learn (Columbus, Ohio: Merrill, 1969).

20. Reynolds, p.276.

21. Ron Zemke and Susan Zemke, " 30 Things We Know for Sure about Adult Learners," in Ron Zemke and others, eds., Designing and Delivering Cost Effective Training - and Measuring Results (Minneapolis: Lakewood, 1981), p.117.

22. Malcolm Knowles, "Training As An Art Form," Training and Development Journal 34:56-58 (Mar. 1980).

23. Jerold W. Wiley, "One-On-One Training: A Solid Bet for Skills," in Zemke, p.157.

24. Stephen D. Brookfield, Understanding and Facilitating Adult Learning (San Francisco: Jossey-Bass, 1986), p.9-20. 
25. Calvin P. Otto and Roland O. Glaser, The Management of Training: A Handbook for Training and Development Personnel (Reading, Mass.: Addison-Wesley, 1970), p.336-39.

26. William R. Tracey, Designing Training and Development Systems, rev. ed. (New York: AMACOM, 1984), p.345-47.

27. John Diebold, Managing Information: The Challenge and the Opportunity (New York: American Management Assn., 1985), p.42-43.

28. Zemke, p.115-17.

29. Francis X. Mahoney, "Designing Your Own Training Workshop," 3-part series, Personnel 62:61-66 (Sept. 1985); 62:61-69 (Oct. 1985); 62:56-66 (Nov. 1985).

30. David D. Cram, "How to Design the Ideal Training Course," in Zemke, p.178-82.

31. Bonnie Juergens, "Staff Training Aspects of Circulation System Implementation," in Matthews, p. 205.

32. Reynolds, p. 275 .

33. Sharon Efroymson, "Managing End-User Training," Computerworld 5:49 (May 5, 1986).

34. Anthony P. Carnevale, "The Learning Enterprise," Training and Development Journal 40:18 (Jan. 1986).

35. Ibid., p. 20.

36. Harold Goldstein and Bryna Shore Fraser, Training for Work in the Computer Age, Research Report Series RR-85-09 (Washington, D.C.: National Commission for Employment Policy, 1985), p.69.

37. Creth, p.96. 


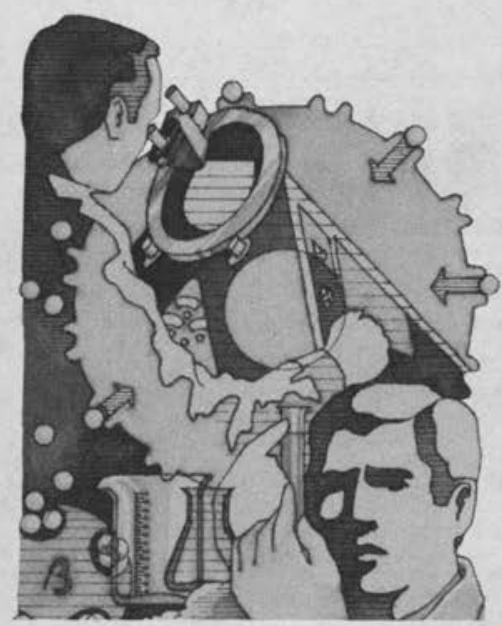

\section{The}

Essential Tool for an Essential Decade

\section{Science Citation Index ${ }^{\circledR}$ 1955-1964}

Limited edition: the Science Citation Index 1955-1964 ... . your connection to the literature of a decade that is essential to today's scientific research.

Essential because researchers are still citing the literature of 1955-1964: over one-half million citations appearing in the 1985 Science Citation Index were to articles published during this period. Much of the information in the $S C I^{\circ} 1955-1964$ has not been available before in a citation index, making it an essential part of every complete science library. And none of the information in the SCI 1955-1964 is available online.

For essential information on this essential tool, fill out and mail the coupon below!

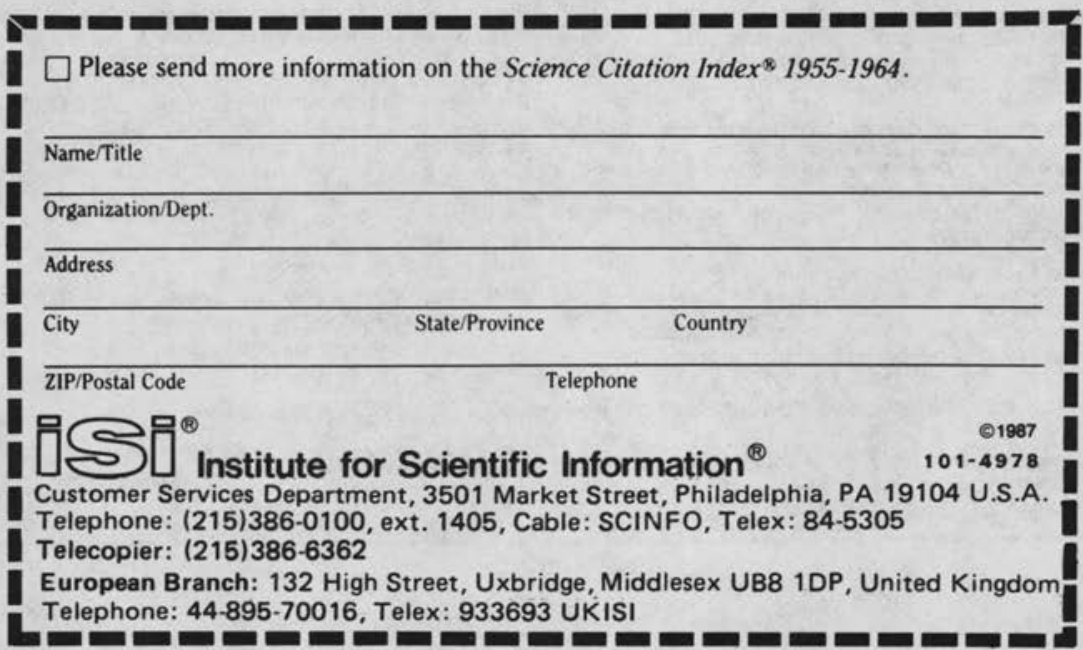




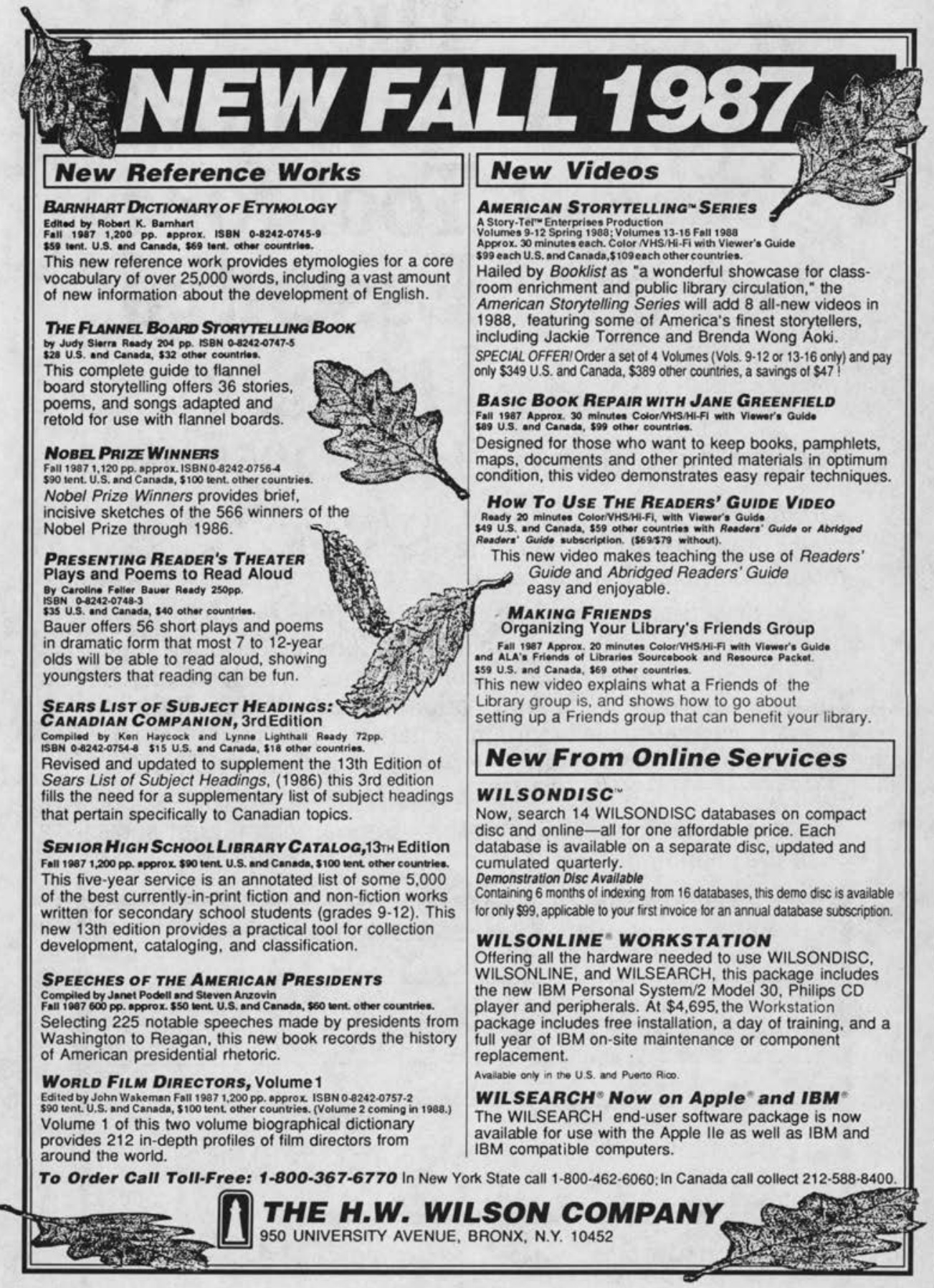

